\title{
Effect of Oxygen Therapy by Venturi Mask versus Non Invasive Ventillation on the Outcome of Patients Who Devolope Hypoxia after Open Heart Surgery
}

\author{
Yousry El-Saied Rizk1, Tarek Samy Essawy², Ahmed Hamdy Abd Elrahman Ali ${ }^{*}$, \\ Mohamed Ahmed El-Gazzar ${ }^{4}$, Abdelkhalek Fouad Mahmoud ${ }^{5}$ \\ ${ }^{1}$ Cardiothoracic Surgery and Department of Critical Care Medicine, Faculty of Medicine, Benha University, Egypt \\ ${ }^{2}$ Department of Chest, Benha University Hospital, Benha, Egypt \\ ${ }^{3}$ Anesthesia and Intensive Care Department, Benha, Egypt \\ ${ }^{4}$ Cardiothoracic Surgery, Benha University, Benha, Egypt \\ ${ }^{5}$ Internal Medicine, Ministry of Health, Cairo, Egypt \\ Email: *ahmed76hamdy@yahoo.com
}

How to cite this paper: El-Saied Rizk, Y., Essawy, T.S., Ali, A.H.A.E., El-Gazzar, M.A. and Mahmoud, A.F. (2018) Effect of Oxygen Therapy by Venturi Mask versus Non Invasive Ventillation on the Outcome of Patients Who Devolope Hypoxia after Open Heart Surgery. Open Journal of Anesthesiology, 8, 241-254.

https://doi.org/10.4236/ojanes.2018.89025

Received: May 24, 2018

Accepted: September 27, 2018

Published: September 30, 2018

Copyright $\odot 2018$ by authors and Scientific Research Publishing Inc. This work is licensed under the Creative Commons Attribution International License (CC BY 4.0).

http://creativecommons.org/licenses/by/4.0/ c) (i) Open Access

\begin{abstract}
Background: Cardiothoracic surgery is a common cause of acute respiratory failure and is associated with increased morbidity and mortality. We aimed to compare the outcomes of open heart surgery patients treated using oxygen delivery devices with patients who receive NIV as a first-line therapy for hypoxemic respiratory failure. Materials and Methods: 40 patients who developed acute hypoxemic respiratory failure after open heart surgery and admitted to cardiothoracic ICU 20 patients received NIV and 20 patient received oxygen by venture mask. For all patients the following measurements were performed before and after CPAP AND Venture use: $\mathrm{CBC}$, blood urea, serum creatinine body temperature, chest X-ray, Arterial blood gases (arterial pH, sodium bicarbonate, $\mathrm{pcO}_{2}, \mathrm{SpO}_{2}$ and $\mathrm{PaO}_{2}$-to- $\mathrm{FiO}_{2}$ ratio). Results: Mean $\mathrm{PO}_{2}$ and $\mathrm{SO}_{2}$ have increased after using of both venture and Cpap, increase in both $\mathrm{PCO}_{2}$ and $\mathrm{HCO}_{3}$ levels after using Venturi mask, CPAP mask was superior to venturi mask in avoiding the need of intubation, decreasing The ICU stay median length and also median length of hospitalization, all were lower in CPAP group than venture group. Also the mortality rate was lower in CPAP group than the venturi group. Conclusion: Using CPAP mask in severe AHRF following open heart surgery can avoid intubation, decreases the levels of tachypnea and arterial hypoxemia, decreases ICU stay, the length of hospitalization and also decreases the mortality rate compared with patients receiving high-concentration oxygen
\end{abstract}


therapy with venture mask.

\section{Keywords}

Open Heart Surgery, Venture Mask, CPAP Mask, Non Invasive

Ventilation, $\mathrm{O}_{2}$ Therapy

\section{Introduction}

Cardiothoracic surgery is a common cause of acute respiratory failure and is associated with increased morbidity and mortality [1]. The reported incidence of postoperative respiratory complications ranges from $5 \%$ to $80 \%$, depending on the patient population and the diagnostic criteria used to define complications [2]. Basal atelectasis is associated with decreased lung compliance, a higher incidence of infection, and prolonged hospital stay [3]. Under normal circumstances, tissue hypoxia occurs within 4 minutes of inadequate tissue oxygenation [4]. Several devices for oxygen delivery are available in critically ill patients, such as a high concentration reservoir mask, simple face mask, Venturi mask, and nasal cannula [5]. The Venturi mask is frequently used because it allows delivery of the predetermined fraction of inspired oxygen $\left(\mathrm{FiO}_{2}\right)$ [5]. The Venturi mask, as all the previously mentioned low-flow systems, provides oxygen at flow rates that are lower than patients' inspiratory demands; thus, when the patient's inspiratory flow exceeds the gas flow rate from the mask, room air is entrained. The final concentration of oxygen truly delivered to the patient can be lower than the set fraction of inspired oxygen $\left(\mathrm{FiO}_{2} \mathrm{SET}\right)$ and depends on the ventilatory demands of the patient [6]. When oxygen therapy is insufficient to correct hypoxemia, Non Invasive ventilation (NIV) is often used to avoid reintubation and improve Outcomes [7]. Several studies have been conducted to show the outcomes of NIV in Acute Hypoxemic Respiratory Failure in many groups of patients. Huang et al. 2017 [8] showed that compared with oxygen therapy, early respiratory support with NIV would significantly reduce mortality, intubation rate and length of intensive care unit (ICU) in immune compromised patients with acute respiratory failure (ARF). Lemiale, et al. 2015 [9] stated that among immune compromised patients admitted to the intensive care unit with hypoxemic acute respiratory failure early noninvasive ventilation compared with oxygen therapy alone did not reduce 28-day mortality. However, study power was limited. There is no previous study comparing the use of venturi mask with noninvasive ventilation after open heart surgery. The aim of this study was to compare the outcomes of open heart surgery patients treated using oxygen delivery devices with patients who receive NIV as a first-line therapy for hypoxemic respiratory failure.

\section{Patients and Methods}

The study was done after approval of the ethical board of Banha University and 
an informed written consent was taken from relatives of patients included in the study. The current study is a prospective randomized clinical trial. It was carried out on 40 patients more than 18 and less than 60 years old who developed acute hypoxemic respiratory failure after open heart surgery and admitted to the cardiothoracic intensive care unit of the Banha university hospital during the period from June to September 2017 Patients were divided into two groups:

Group I: consisted of 20 patients received NIV.

Group II: consisted of 20 patients received oxygen by venturi mask.

Table 1 shows the Demographic data for studied groups. Mean age of patients was $55.31 \pm 5.998$ years, while 23 were male patients, 17 were female.

Table 2 shows the Clinical characteristics for studied groups. Of the patients enrolled in the study, 6 were suffering from COPD, 33 had hypertension, and 11 had diabetes while 17 were smokers or ex-smokers.

An informed written consent was obtained from relatives of all patients before getting them involved in the study. The steps of the study, the aim of the work, the potential benefits and hazards were discussed with all the relatives. We excluded from our study, patients with Abnormalities that precluded proper fit of the interface (agitated or uncooperative patient), patients who have inability to protect the airway (excess secretions, stupors, or comatose patient), patients with medically unstable condition (e.g., hypotension, uncontrolled cardiac ischemia/arrhythmia), patients with facial trauma or burns, facial surgery, or facial anatomical abnormality), patients with body mass index (BMI) more than or equal to 35 patients with respiratory arrest with the need for immediate endotracheal intubation, patients have a primary respiratory disease and lastly $\mathrm{Pa}$ tients with multiple organ dysfunctions. All participants to the study were subjected to complete physical examination. For all patients the following parameters were performed: heart rate, systolic blood pressure, respiratory rate, body temperature, chest X-ray, Arterial blood gases, arterial potential hydrogen $(\mathrm{pH})$, sodium bicarbonate $\left(\mathrm{HCO}_{3}\right)$, partial pressure of carbon dioxide $\left(\mathrm{pacO}_{2}\right)$, blood oxygen saturation $\left(\mathrm{SpO}_{2}\right)$ and partial pressure of oxygen to the fraction of inspired oxygen $\left(\mathrm{PaO}_{2}\right)$-to- $\mathrm{FiO}_{2}$ ratio. All parameters were performed according to conventional methods used in Banha University Hospital Clinical Pathology Department.

All previous parameters were measured at the start of the study before using continuous positive airway pressure (CPAP) mask or Venturi mask 20 patients have been treated with CPAP mask and 20 patients treated with Venturi mask, after which the same previously mentioned parameters were measured again at the end of the study.

\section{Applying Venturi mask to 20 patients (Venturi group)}

For that device we used a variable $\mathrm{FIO}_{2}$ Venturi mask, which has a graded adjustment of the air entrainment port. We used different ports for each patient. The least port giving $\mathrm{FIO}_{2}$ that achieve $\mathrm{SpO}_{2}>92 \%$ was selected. The presence of air leaks, obstruction distal to the jet orifice, and occlusion of the exhalation 
Table 1. Demographic data for studied group.

\begin{tabular}{ccc}
\hline & & Patient group (No. = 40) (\%) \\
\hline \multirow{2}{*}{ Sex } & Female & $17(42.5 \%)$ \\
& Male & $23(57.5 \%)$ \\
Age(year) & Mean \pm SD & $51.31 \pm 5.998$ \\
& Minimum (39) & Maximum (60) \\
\hline
\end{tabular}

Mean age of patients was $55.31 \pm 5.998$ years, while 23 were male patients, 17 were female.

Table 2. Clinical characteristics for studied group.

\begin{tabular}{ccc}
\hline & No. of patients & $\%$ \\
\hline COPD & 6 & 15 \\
Hypertension & 33 & 82.5 \\
Diabetes & 11 & 27.5 \\
Smoker/ex-smoker & 17 & 42.5 \\
\hline
\end{tabular}

Of the patients enrolled in the study, 6 were suffering from COPD, 33 had hypertension, and 11 had diabetes while 17 were smokers or ex-smokers.

ports were frequently assessed, and the patient was constantly encouraged and reassured. We avoid using aerosol devices with the venturi.

\section{Applying NIV to 20 patients (NIV group)}

The NIV was administered with the use of a portable noninvasive ventilator. The detailed procedure of NIV was explained to the patient for improving compliance. The NIV was delivered to patients in bed, at an angle of $30^{\circ}-45^{\circ}$, and in all patients a full face mask was used as an interface for delivery of the NIV. At the outset the patient was started on an inspiratory pressure of 8 centimeters of water $\left(\mathrm{cm} \mathrm{H}_{2} \mathrm{O}\right)$ and expiratory pressure of $4 \mathrm{~cm} \mathrm{H}_{2} \mathrm{O}$. The inspiratory and expiratory pressure were titrated in increments of $2 \mathrm{~cm} \mathrm{H}_{2} \mathrm{O}$, based on continuous pulse oximetry (to achieve arterial oxygen saturation [measured via pulse oximetry] of 92\%); arterial blood gases (at 1 hour and 4 hours, and periodically thereafter as clinically indicated); subjective alleviation of patient's dyspnea; decrease in respiratory rate; and good patient-ventilator synchrony; or until a maximum inspiratory pressure of $20 \mathrm{~cm} \mathrm{H}_{2} \mathrm{O}$ and expiratory pressure of $10 \mathrm{~cm}$ $\mathrm{H} 2 \mathrm{O}$ was reached. Oxygen supplementation was provided through a port in the mask, to keep arterial oxygen saturation more than $92 \%$. The presence of air leaks was frequently assessed, and the patient was constantly encouraged and reassured. The NIV was applied continuously for as long as possible in the first 24 hours. Patients were allowed intermittent periods off the NIV, for eating or expectoration of secretions, and during that period they were given oxygen through an air-entrainment mask, with $\mathrm{FIO}_{2}$ of 0.5. Weaning from NIV was done by reducing the duration of NIV to 6 - 8 hours per day. At that point, if the respiratory rate remained below 25 breaths/minute and $\mathrm{PaO}_{2}$ was above 70 millimeter of mercury $(\mathrm{mm} \mathrm{Hg})$ without any ventilatory support, the NIV was defi- 
nitively withdrawn. Appropriate medical therapy was administered in addition to the NIV, as required.

\section{End points}

The primary outcome was NIV, or venturi failure, defined as the need for endotracheal intubation during the ICU stay. Generally, the following criteria indicated the need for tracheal intubation: inability to improve or stabilize gas exchange, or dyspnea in 1 hour; failure to improve agitation from hypoxemia or changes in mental status linked to respiratory impairment; bradycardia (heart rate: 60 beats/minute with altered mental status); hypotension (systolic blood pressure: $90 \mathrm{~mm} \mathrm{Hg}$ ); respiratory arrest; failure to maintain $\mathrm{SpO}_{2}: 88 \%$; significant metabolic and/or respiratory acidosis ( $\mathrm{pH}: 7.20)$. Ultimately, clinical judgment was applied in the decision to intubate any patient, and was left to the intensivist's clinical judgment.

\section{Statistical Analysis}

Data was collected, coded, revised and entered to the Statistical Package for Social Science (IBM SPSS) version 20.

The data have been presented as numbers and percentages for qualitative data, mean, standard deviations and ranges for the quantitative data with parametric distribution and median with interquartile range (IQR) for the quantitative data with non-parametric distribution.

The Paired t-test was used in comparing the two groups having quantitative data with parametric distribution and Wilxon Rank test was used to compare the two groups having qualitative data with non-parametric distribution. The Independent t-test was used in the comparison between the two groups with quantitative data and parametric distribution and Mann-Whitney test was used in the comparison between two groups with quantitative data and non-parametric distribution [8]. Spearman correlation coefficients were used to assess the significant relation between two quantitative parameters in the same group [9]. The Chi-square test was used to compare two groups having qualitative data. The Fischer exact test was used also to compare two groups having low number of qualitative data. $\mathrm{P}$ value $<0.05$ is considered to be significant, $\mathrm{P}=0.051-0.070$ is considered to be borderline significant, $\mathrm{P}>0.070$ is considered non-significant.

\section{Discussion}

Respiratory complications are a major cause of post-operative morbidity after open-heart surgery [10]. During the evolution of severe acute hypoxemic respiratory failure (AHRF), patients may require intubation and mechanical ventilation as a life-support measure while concomitant treatments for the underlying disease are instituted. In these patients, however, invasive mechanical ventilation is associated with an important incidence of complications and mortality [11]. The use of noninvasive ventilation (NIV) as an alternative to immediate intuba- 
tion in these patients reduced the incidence of serious complications and length of stay in one study [12]. At the start of the study during hypoxia the blood pressure, heart rate and respiratory rate were high with a significant decrease in Mean Heart rate, Respiratory rate, Systolic and Diastolic blood pressure after treatment with CPAP and Venturi masks (Figure 1, Figure 2, Table 4, Table 5), which reflected the improvement in patients' symptoms and their vital signs after using both CPAP and Venturi masks. The mean heart rate before therapy was $108.57 \pm 8.811$ Beat/minute; mean respiratory rate was $21.80 \pm 3.560$ Breath/minute while the mean Systolic blood pressure was $146 \pm 24.578 \mathrm{~mm} \mathrm{Hg}$ and mean Diastolic blood pressure was $88.5 \pm 12.310 \mathrm{~mm} \mathrm{Hg}$. Eugene 2000 [13] stated that acute hypoxia leads to stimulation of the peripheral chemoreceptors, which in turn directly increase sympathetic outflow. Marshall, 1994; Reis et al. 1994 [14] [15] also stated that acute hypoxia, sensed by the peripheral and medullary chemoreceptors, is a powerful activator of the sympathetic nervous system as reflected by the increase of systemic and regional sympathetic tone during acute hypoxia. Hypoxia-mediated sympathetic activation is currently envisaged as a defence mechanism to assure oxygen supply to critical organs by means of raising cardiac output and regulating regional conductances (Rowell et al. 1989; Leuenberger et al. 1991; Calbet, 2000 [16] [17] [18]). There was a Positive significant correlation between Respiratory rate and $\mathrm{PH}$ and also a significant negative correlation existed between Respiratory rate and both $\mathrm{PaCO}_{2}$ and Bicarbonate $\left(\mathrm{HCO}_{3}\right)$ levels (Table 3$)$. The relationship between respiratory rate and both $\mathrm{PaCO}_{2}$ level and $\mathrm{PH}$ is well known and it is due to Carbon dioxide emissions by rapid breathing, which will result in decrease $\mathrm{PaCO}_{2}$ level which will increase $\mathrm{PH}$ resulting in respiratory alkalosis.

Also There was a negative significant correlation between heart rate and both $\mathrm{PaO}_{2}$ and $\mathrm{SO}_{2}$ levels (Table 3). We mentioned this relationship before which was also discussed by Eugene 2000; Marshall, 1994; Reis et al. 1994 [13] [14] [15], also a positive significant correlation between $\mathrm{PaCO}_{2}$ level and white blood cell count and a negative significant correlation between $\mathrm{PaCO}_{2}$ level and Diastolic blood pressure. For our knowledge this last two relationships were not mentioned in any study before. Also, we found a significant decrease in Mean Heart rate, Respiratory rate, and Systolic blood pressure after treatment with CPAP and Venturi masks (Figure 1, Figure 2, Table 4, Table 5), which reflected the improvement in patients' symptoms and their vital signs after using both CPAP and Venturi masks. Also, we found a significant decrease in Diastolic blood pressure after using CPAP but not Venturi mask. We could not identify why the diastolic blood pressure was reduced in CPAP group and did not decrease in Venturi group.

The previous improvement in vital signs is due to the beneficial effect of both CPAP and Venturi masks in treating hypoxia and improving gas exchange as we mentioned before "acute hypoxia, sensed by the peripheral and medullary chemoreceptors, is a powerful activator of the sympathetic nervous 
system as reflected by the increase of systemic and regional sympathetic tone during acute hypoxia". In both CPAP and Venturi groups respectively there were a significant increase in mean $\mathrm{PaO}_{2}$ and $\mathrm{SpO}_{2}$ after using of both venturi and CPAP. Mean $\mathrm{PaO}_{2}$ in the CPAP group before treatment was $62.3 \mathrm{~mm} \mathrm{Hg}$ and increased after treatment to $78 \mathrm{~mm} \mathrm{Hg}$ while mean $\mathrm{SO}_{2}$ before treatment was $88.6 \%$ and increased to $93.5 \%$ after treatment. In venturi group mean $\mathrm{PaO}_{2}$ before treatment was $65.25 \mathrm{~mm} \mathrm{Hg}$ and increased with venturi to 80.75 $\mathrm{mm} \mathrm{Hg}$ while mean $\mathrm{SpO}_{2}$ before treatment was $89.95 \%$ and increased with treatment to $93.25 \%$ (Table 6, Table 7, Figure 3, Figure 4).

Ritesh et al. 2009 [19] stated that there was significant improvement in clinical and blood gas values with the use of NIV in cases of AHRF. Melvin et al. 1967 [20] also found increase in both $\mathrm{PaO}_{2}$ and $\mathrm{SpO}_{2}$ levels with venturi use. This was due to improvement in gas exchange as we mentioned before. Both $\mathrm{PaCO}_{2}$ and $\mathrm{HCO}_{3}$ levels showed a significant increase after using Venturi mask. The average rising in $\mathrm{PaCO}_{2}$ was $2.55 \mathrm{~mm} \mathrm{Hg}$. Melvin et al. 1967 [20] was in agreement when he found that the average increase in $\mathrm{PaCO}_{2}$ level was $2 \mathrm{~mm}$ and no patient had a rise greater than $7 \mathrm{~mm} \mathrm{Hg}$. Table 8, Table 9 and Figures 5-8 show the superiority of CPAP over venturi mask. While 13 patients from 20 improved on $\mathrm{CPAP}$ and 7 patients need invasive intubation (65\% success rate) only $11 \mathrm{pa}-$ tients from 20 improve on Venturi and 9 patients need intubation (55\% success rate). The superiority of CPAP over Venturi mask appeared again when we compared the length in ICU stay, duration of hospitalization and the mortality rate between the two groups. The ICU stay median length was 20 hours in the CPAP group vs. 26 hours in venturi group while the median duration of hospitalization was 11 days in the CPAP group vs. 15 days in the Venturi group. Also the mortality rate was higher in the Venturi group than CPAP group, while 4 patients of 20 died from Venturi group only two patients died from CPAP group. Ritesh et al. 2009 [19] were in agreement with our findings. These authors found that the application of the NIV is associated with an initial improvement in gas exchange, and its application can avoid intubation in almost 53\% of patients with AHRF. Zhu et al. 2013 [21] also stated that Both reintubation and mortality rates decreased significantly with noninvasive ventilation in the single published randomized study after heart surgery; the frequency of reintubation decreased from $80.9 \%$ to $18.8 \%$. Auriant et al. 2001 [21] stated that when noninvasive ventilation used to treat respiratory failure, the need for subsequent intubation ranges from $19 \%$ to $30 \%$. The CPAP failure rate in our study was 35\% (higher than Auriant et al. 2001 [22]), this may be due to difference in modes selected. Virginie et al. 2015 [23] was one of the studies whose results were the closest to our results. In this study the proportion of patients requiring intubation was $38.2 \%$ in patients treated with noninvasive ventilation. Ferrer et al. 2003 [24] also were in agreement with our findings. These authors found that the use of NIV to avoid intubation in patients with severe AHRF decreased the need for intubation, and also decreased the levels of tachypnea and arterial hy- 
poxemia, and improved ICU and 90-day survival compared with patients receiving high-concentration oxygen therapy.

Table 3. Significant Correlation between Arterial blood gases parameters and all other studied parameters in all patients before and after treatment.

\begin{tabular}{|c|c|c|c|c|c|c|c|c|c|c|}
\hline \multirow{2}{*}{$\begin{array}{l}\text { All patients } \\
\text { before ttt }\end{array}$} & \multicolumn{2}{|c|}{$\mathrm{PH}$} & \multicolumn{2}{|c|}{$\mathrm{PCO}_{2}$} & \multicolumn{2}{|c|}{$\mathrm{HCO}_{3}$} & \multicolumn{2}{|c|}{$\mathrm{PO}_{2}$} & \multicolumn{2}{|c|}{$\mathrm{SO}_{2}$} \\
\hline & $\mathbf{R}$ & P-value & $\mathbf{R}$ & P-value & $\mathbf{R}$ & P-value & $\mathbf{R}$ & P-value & $\mathbf{R}$ & P-value \\
\hline Heart rate & -0.115 & 0.479 & 0.069 & 0.672 & 0.136 & 0.403 & -0.247 & 0.124 & -0.327 & 0.039 \\
\hline Respiratory rate & 0.493 & 0.001 & -0.680 & 0.000 & -0.550 & 0.000 & 0.117 & 0.472 & 0.180 & 0.268 \\
\hline \multicolumn{11}{|c|}{ After Venturi mask } \\
\hline Heart rate & -0.218 & 0.367 & 0.109 & 0.646 & 0.413 & 0.071 & -0.638 & 0.002 & -0.657 & 0.002 \\
\hline Respiratory rate & 0.688 & 0.001 & -0.908 & 0.000 & -0.626 & 0.003 & 0.238 & 0.313 & 0.223 & 0.345 \\
\hline WBCs thous $/ \mathrm{cmm}$ & -0.393 & 0.086 & 0.518 & 0.019 & 0.296 & 0.205 & -0.382 & 0.096 & 0.418 & 0.067 \\
\hline \multicolumn{11}{|c|}{ After CPAP mask } \\
\hline Respiratory rate & 0.384 & 0.095 & -0.651 & 0.002 & -0.256 & 0.275 & 0.096 & 0.686 & 0.162 & 0.598 \\
\hline $\begin{array}{c}\text { Diastolic blood } \\
\text { pressure }\end{array}$ & 0.117 & 0.622 & -0.497 & 0.026 & -0.258 & 0.272 & 0.355 & 0.124 & 0.350 & 0.130 \\
\hline
\end{tabular}

Before therapy in both groups: Heart rate had a negative correlation to $\mathrm{SO}_{2}$ level. Respiratory rate had a positive correlation to $\mathrm{PH}$ level and a negative correlation to $\mathrm{PCO}_{2}$ and $\mathrm{HCO}_{3}$ levels. After Venturi mask: Heart rate had a negative correlation to both $\mathrm{PO}_{2}$ and $\mathrm{SO}_{2}$ levels. Respiratory rate had a positive correlation to $\mathrm{PH}$ level and a negative correlation to $\mathrm{PCO}_{2}$ and $\mathrm{HCO}_{3}$ levels. White blood cell (WBC) count had a positive correlation to $\mathrm{PCO}$ level? After CPAP mask: Respiratory rate had a negative correlation to $\mathrm{PCO}_{2}$ level and a negative correlation to $\mathrm{PCO}_{2}$ and $\mathrm{HCO}_{3}$ levels. Diastolic blood pressure had a negative correlation to $\mathrm{PCO}_{2}$ level.

Table 4. Comparison between vital signs values before and after using CPAP mask.

\begin{tabular}{|c|c|c|c|c|c|c|}
\hline & \multicolumn{2}{|c|}{$\begin{array}{c}\text { Cpap before } \\
(\text { No. }=)\end{array}$} & \multicolumn{2}{|c|}{$\begin{array}{c}\text { Cpap after } \\
(\text { No. }=)\end{array}$} & \multicolumn{2}{|c|}{ Paired t-test } \\
\hline & Mean & $\mathrm{SD}$ & Mean & $\mathrm{SD}$ & $\mathrm{t}$ & P-value \\
\hline Heart rate & 109.650 & 8.963 & 101.050 & 7.380 & 5.888 & 0.001 \\
\hline Respiratory rate & 21.5 & 3.069 & 19.8 & 1.936 & 3.747 & 0.001 \\
\hline Diastolic blood pressure & 91 & 13.337 & 83.50 & 9.330 & 3.684 & 0.002 \\
\hline
\end{tabular}

After Using CPAP mask, there were a significant decrease in mean heart rate, respiratory rate, systolic and diastolic blood pressures.

Table 5. Comparison between vital signs values before and after using venturi mask.

\begin{tabular}{|c|c|c|c|c|c|c|}
\hline & \multicolumn{2}{|c|}{$\begin{array}{l}\text { Venturi before } \\
(\text { No. }=20)\end{array}$} & \multicolumn{2}{|c|}{$\begin{array}{l}\text { Venturi after } \\
(\text { No. }=20)\end{array}$} & \multicolumn{2}{|c|}{ Paired t-test } \\
\hline & Mean & SD & Mean & SD & $\mathrm{T}$ & P-value \\
\hline Heart rate & 107.50 & 8.751 & 103.40 & 12.365 & 2.732 & 0.013 \\
\hline Respiratory rate & 22.1 & 4.051 & 20.1 & 4.229 & 4.414 & 0.000 \\
\hline Diastolic blood pressure & 86 & 10.954 & 85 & 13.179 & 0.567 & 0.577 \\
\hline
\end{tabular}

In venturi group there were a significant decrease in mean heart rate, respiratory rate, and systolic blood pressures. No significant changes occurred in Diastolic blood pressure. 
Table 6. Comparison between arterial blood gases values before and after using CPAP mask.

\begin{tabular}{ccccccc}
\hline & \multicolumn{2}{c}{$\begin{array}{c}\text { CPAP before } \\
\text { (No. }=)\end{array}$} & \multicolumn{2}{c}{$\begin{array}{c}\text { CPAP after } \\
(\text { No. }=)\end{array}$} & \multicolumn{2}{c}{ Paired t-test } \\
\cline { 2 - 7 } & Mean & SD & Mean & SD & T & P-value \\
\hline $\mathrm{PH}$ & 7.3935 & 0.7909 & 7.3850 & 0.6985 & 1.509 & 0.148 \\
$\mathrm{PCO}_{2}$ & 38.3000 & 9.6250 & 39.9000 & 8.0452 & -1.902 & 0.072 \\
$\mathrm{HCO}_{3}$ & 23.9500 & 3.1199 & 24.4500 & 2.7042 & -1.453 & 0.163 \\
$\mathrm{PO}_{2}$ & 62.3000 & 9.0907 & 78.0500 & 14.7129 & -8.064 & 000 \\
$\mathrm{SO}_{2}$ & 88.6000 & 2.8172 & 93.5500 & 4.3706 & -7.854 & 000 \\
\hline
\end{tabular}

In CPAP group our results show a significant increase of each of mean $\mathrm{PO}_{2}$ and $\mathrm{SO}_{2}$ levels. No changes occurred in $\mathrm{PH}, \mathrm{PCO}_{2}$ or $\mathrm{HCO}_{3}$ levels.

Table 7. Comparison between arterial blood gases values before and after venturi.

\begin{tabular}{ccccccc}
\hline & \multicolumn{2}{c}{ Venturi before (No. $=)$} & \multicolumn{2}{c}{ Venturi after $($ No. $=)$} & \multicolumn{2}{c}{ Paired t-test } \\
\cline { 2 - 7 } & Mean & SD & Mean & SD & T & P-value \\
\hline $\mathrm{PH}$ & 7.403 & 0.095 & 7.393 & 0.099 & 1.530 & 0.142 \\
$\mathrm{PCO}_{2}$ & 36.15 & 9.080 & 38.7 & 11.805 & -2.091 & 0.050 \\
$\mathrm{HCO}_{3}$ & 22.5 & 3.501 & 23.25 & 3.611 & -5.251 & 0.000 \\
$\mathrm{PO}_{2}$ & 65.25 & 12.353 & 80.75 & 24.174 & -3.568 & 0.002 \\
$\mathrm{SO}_{2}$ & 89.95 & 3.017 & 93.25 & 4.689 & -3.789 & 0.001 \\
\hline
\end{tabular}

In venturi group there was a significant increase in mean $\mathrm{PCO}_{2}, \mathrm{HCO}_{3} \mathrm{PO}_{2}$ and $\mathrm{SO}_{2}$ levels. No changes occurred in PH level.

Table 8. Comparison between Non Invasive group and Venturi group according to the rate of tracheal intubation and the mortality rate.

\begin{tabular}{|c|c|c|c|c|c|c|}
\hline & \multicolumn{2}{|c|}{$\begin{array}{c}\text { Noninvasive (CPAP) group. } \\
\text { No. }=20\end{array}$} & \multicolumn{2}{|c|}{$\begin{array}{l}\text { Venturi group. } \\
\text { No. }=20\end{array}$} & \multicolumn{2}{|c|}{ Chi square test } \\
\hline & No. & $\%$ & No. & $\%$ & $\mathrm{~T}$ & P-value \\
\hline $\begin{array}{l}\text { Need for } \\
\text { intubation }\end{array}$ & 7 & $35 \%$ & 9 & $45 \%$ & 0.253 & 0.042 \\
\hline Mortality & 4 & $20 \%$ & 7 & $35 \%$ & 1.068 & 0.031 \\
\hline
\end{tabular}

CPAP mask was superior to venturi in decreasing the rate of endotracheal intubation and the mortality rate.

Table 9. Comparison between Non Invasive group and Venturi group according to ICU stay median length in hours, the duration of hospitalization in days.

\begin{tabular}{ccccccc}
\hline & & $\begin{array}{c}\text { Noninvasive (CPAP) } \\
\text { group. No. }=20\end{array}$ & Venturi group. & \multicolumn{2}{c}{ Chi square test } \\
\cline { 5 - 6 } & Median & 20 & T & P-value \\
\hline $\begin{array}{c}\text { ICU stay median } \\
\text { length (hours) }\end{array}$ & $\begin{array}{c}\text { (IQR) } \\
\text { duration of } \\
\text { hospitalization (days) }\end{array}$ & Mean \pm SD & $11 \pm 1.50$ & $14 \pm 2.80$ & -1.697 & 0.031 \\
\hline
\end{tabular}

CPAP mask was superior to venturi in decreasing the ICU stay median length and the duration of hospitalization. 


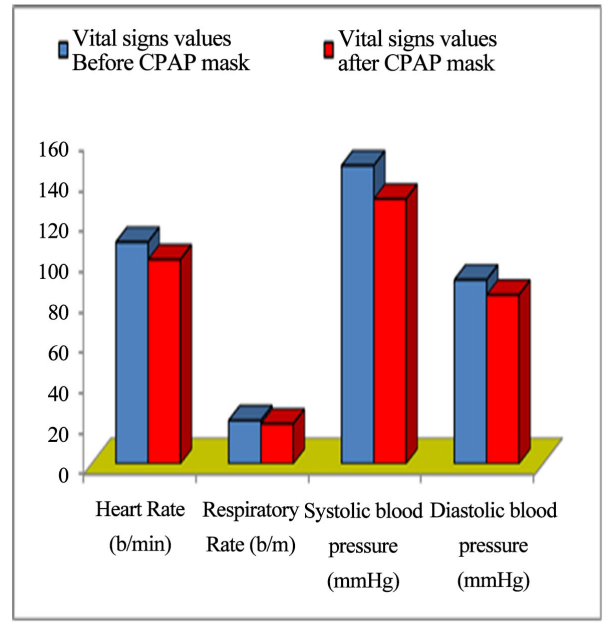

Figure 1. Showing Comparison between vital signs before and after Cpap use. After Using CPAP mask, there were a significant decrease in mean heart rate, respiratory rate, systolic and diastolic blood pressures.

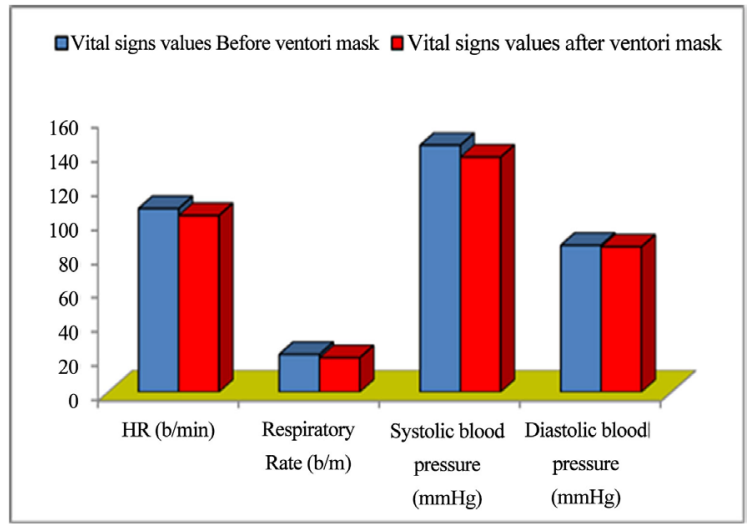

Figure 2. Showing Comparison between vital signs before and after venturi use. In venturi group there were a significant decrease in mean heart rate, respiratory rate, and systolic blood pressures. No significant changes occurred in Diastolic blood pressure.

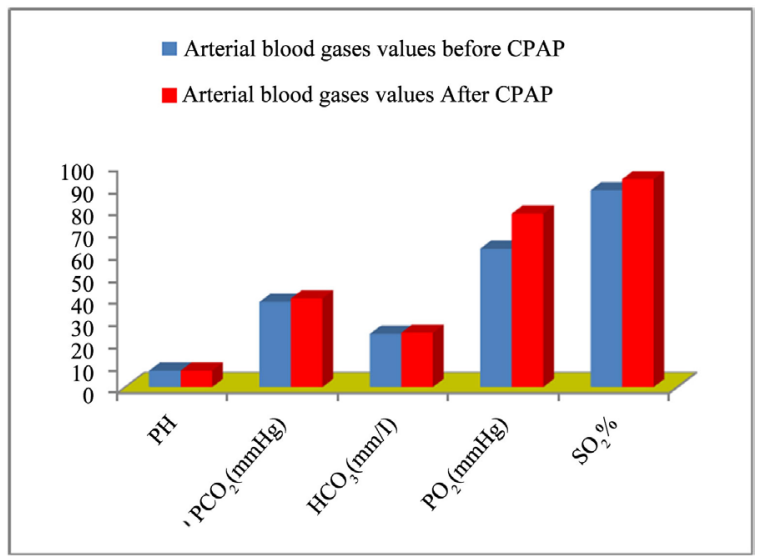

Figure 3. Showing Comparison between arterial blood gases values before and after Cpap use. A significant increase of each of mean $\mathrm{PO}_{2}$ and $\mathrm{SO}_{2}$ levels. 


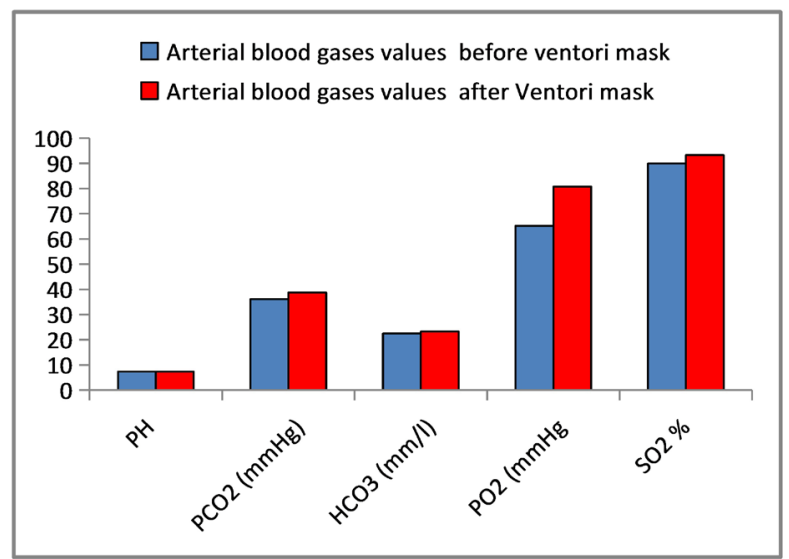

Figure 4. Showing Comparison between ABG parameters before and after venturi use. There was a significant increase in mean $\mathrm{PCO}_{2}$, $\mathrm{HCO}_{3}, \mathrm{PaO}_{2}$ and $\mathrm{SO}_{2}$ levels. No changes occurred in $\mathrm{PH}$ level.

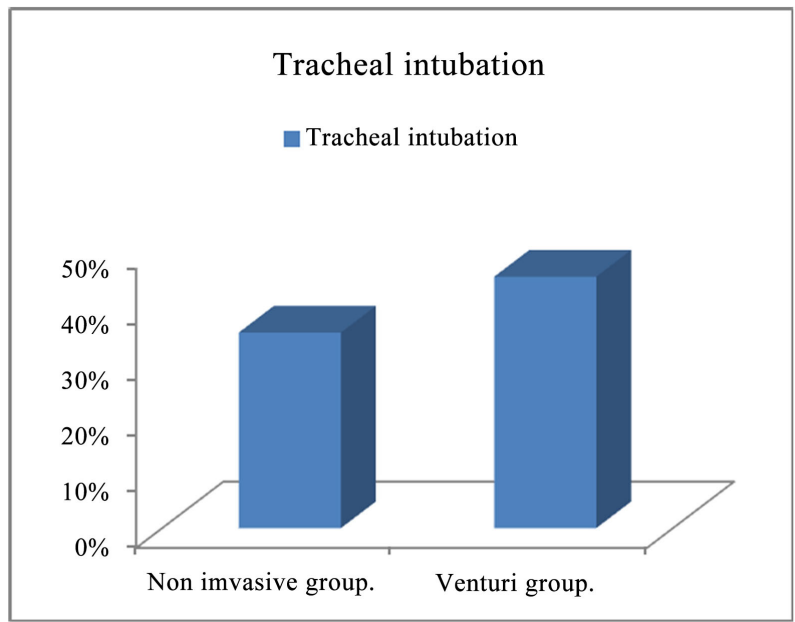

Figure 5. Showing the percentage of patients who need tracheal intubation in both groups.

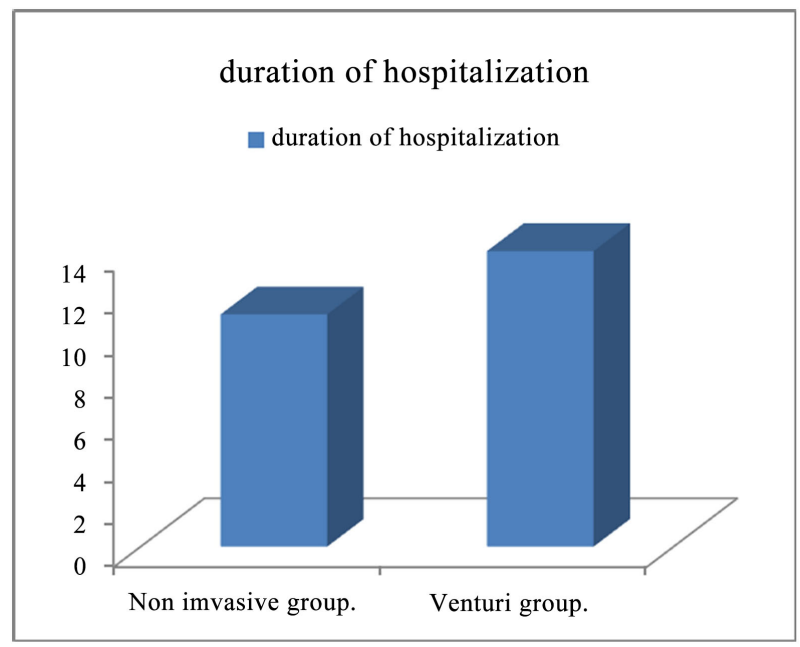

Figure 6. Showing a comparison between both groups according to duration of hospitalization in days. 


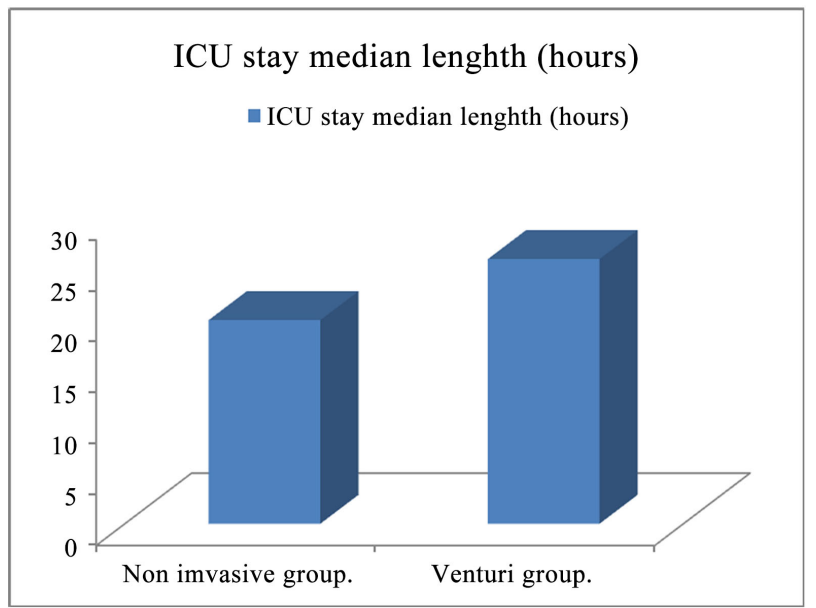

Figure 7. Showing a comparison between both groups according to the ICU stay median length in hours.

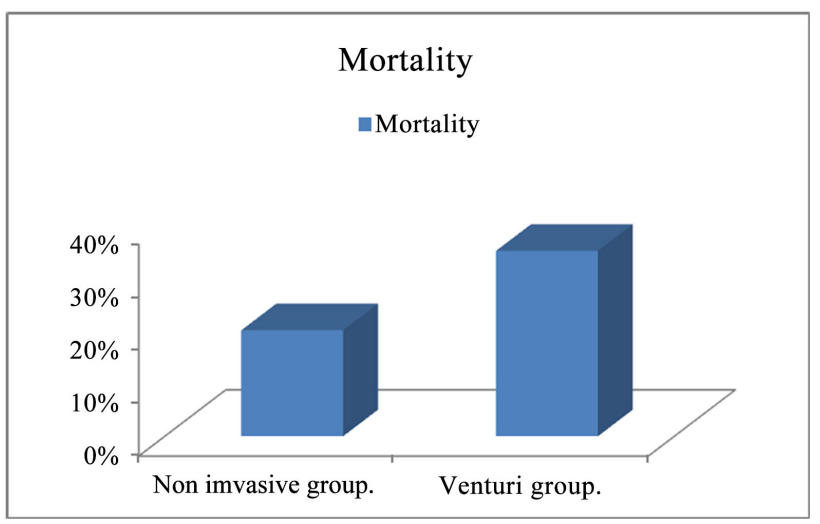

Figure 8. Showing a comparison between both groups according to the mortality rate.

\section{Conclusion}

Using CPAP mask in severe AHRF following open heart surgery can avoid intubation, decreases the levels of tachypnea and arterial hypoxemia, decreases ICU stay, the length of hospitalization and also decreases the mortality rate compared with patients receiving high-concentration oxygen therapy with venturi mask.

\section{Limitations}

Our study has several limitations. First, we study only patients with AHRF after open heart surgery so this study could not apply for all of the patients having general anesthesia. Second, the retrospective nature of the study might have induced selection bias despite the careful classification of patients included in the analysis. Indeed, the baseline characteristics of patients were not similarly as the most severe patients might have been more frequently treated with NIV than with Venturi mask. The Third limitation is the small number of patients used in our study. Studies with large numbers comparing use of Ven- 
turi vs. noninvasive ventilation in patients with AHRF after open heart surgery are needed.

\section{Conflicts of Interest}

The authors declare no conflicts of interest regarding the publication of this paper.

\section{References}

[1] Ranucci, M., Ballotta, A., La Rovere, M.T., et al. (2014) Postoperative Hypoxia and Length of Intensive Care Unit Stay after Cardiac Surgery: The Underweight Paradox? PLoS ONE, 9, e93992. https://doi.org/10.1371/journal.pone.0093992

[2] Xaráa, D., Santosa, A. and Abelha, F. (2015) Adverse Respiratory Events in a Post-Anesthesia Care Unit. Archivos de Bronconeumología, 51, 69-75.

[3] Al Jaaly, E., Fiorentino, F., Barnaby, C., et al. (2013) Effect of Adding Postoperative Noninvasive Ventilation to Usual Care to Prevent Pulmonary Complications in Patients Undergoing Coronary Artery Bypass Grafting: A Randomized Controlled Trial. The Journal of Thoracic and Cardiovascular Surgery, 146, 912-918. https://doi.org/10.1016/j.jtcvs.2013.03.014

[4] Bateman, N.T. and Leach, R.M. (1998) Acute Oxygen Therapy. British Medical Journal, 317, 798-801. https://doi.org/10.1136/bmj.317.7161.798

[5] Maggiore, S.M., Idone, F.A., et al. (2014) Nasal High-Flow versus Venturi Mask Oxygen Therapy after Extubation. Effects on Oxygenation, Comfort, and Clinical Outcome. American Journal of Respiratory and Critical Care Medicine, 190, 282-288. https://doi.org/10.1164/rccm.201402-0364OC

[6] Chanques, G., Riboulet, F., Molinari, N., et al. (2013) Comparison of Three High Flow Oxygen Therapy Delivery Devices: A Clinical Physiological Cross-Over Study. Minerva Anestesiologica, 79, 1344-1355.

[7] Ozsancak Ugurlu, A., Sidhom, S.S., Khodabandeh, A., et al. (2014) Use and Outcomes of Noninvasive Positive Pressure Ventilation in Acute Care Hospitals in Massachusetts. Chest, 145, 964-971. https://doi.org/10.1378/chest.13-1707

[8] Huang, H.-B., Xu, B., Liu, G.-Y., et al. (2017) Use of Noninvasive Ventilation in Immunocompromised Patients with Acute Respiratory Failure: A Systematic Review and Meta-Analysis. Critical Care, 21, 4. https://doi.org/10.1186/s13054-016-1586-9

[9] Lemiale, V., Mokart, D., Resche-Rigon, M., et al. (2015) Effect of Noninvasive Ventilation vs Oxygen Therapy on Mortality among Immunocompromised Patients with Acute Respiratory Failure. JAMA, 314, 1711-1719.

https://doi.org/10.1001/jama.2015.12402

[10] Braun, S.R., Birnbaum, M.L. and Chopra, P.S. (1973) Pre- and Postoperative Pulmonary Function Abnormalities in Coronary Artery Revascularization Surgery. Chest, 73, 316-320. https://doi.org/10.1378/chest.73.3.316

[11] Torres, A., El-Ebiary, M., Marrades, R., Miro, J.M, Gatell, J.M., Sanchez-Nieto, J.M., Xaubet, A., Agusti, C. and Rodriguez-Roisin, R. (1995) Aetiology and Prognostic Factors of Patients with AIDS Presenting Life-Threatening Acute Respiratory Failure. European Respiratory Journal, 8, 1922-1928. https://doi.org/10.1183/09031936.95.08111922

[12] Antonelli, M., Conti, G., Rocco, M., Bufi, M., Deblasi, R.A., Vivino, G., Gasparetto, 
A. and Meduri, G.U. (1998) A Comparison of Noninvasive Positive-Pressure Ventilation and Conventional Mechanical Ventilation in Patients with Acute Respiratory Failure. The New England Journal of Medicine, 339, 429-435. https://doi.org/10.1056/NEJM199808133390703

[13] Fletcher, E.C. (2000) Effect of Episodic Hypoxia on Sympathetic Activity and Blood Pressure. Respiration Physiology, 119, 189-197.

[14] Marshall, J.M. (1994) Peripheral Chemoreceptors and Cardiovascular Regulation. Physiological Reviews, 74, 543-594. https://doi.org/10.1152/physrev.1994.74.3.543

[15] Reis, D.J., Golanov, E.V., Ruggiero, D.A. and Sun, M.K. (1994) Sympatho-Excitatory Neurons of the Rostral Ventrolateral Medulla Are Oxygen Sensors and Essential Elements in the Tonic and Reflex Control of the Systemic and Cerebral Circulations. Journal of Hypertension Supplement, 12, 159-180.

[16] Rowell, L.B., Johnson, D.G., Chase, P.B., Comess, K.A. and Seals, D.R. (1989) Hypoxemia Raises Muscle Sympathetic Activity but Not Norepinephrine in Resting Humans. Journal of Applied Physiology, 66, 1736-1743. https://doi.org/10.1152/jappl.1989.66.4.1736

[17] Leuenberger, U., Gleeson, K., Wroblewski, K., Prophet, S., Zelis, R., Zwillich, C. and Sinoway, L. (1991) Norepinephrine Clearance Is Increased during Acute Hypoxemia in Humans. American Journal of Physiology, 261, 1659-1664.

[18] Calbet, J.A. (2000) Oxygen Tension and Content in the Regulation of Limb Blood Flow. Acta Physiologica Scandinavica, 168, 465-472. https://doi.org/10.1046/j.1365-201x.2000.00698.x

[19] Ritesh Agarwal, D.M., Ajay Handa, D.M., Ashutosh, N., Aggarwal, D.M., et al. (2009) Outcomes of Noninvasive Ventilation in Acute Hypoxemic Respiratory Failure in a Respiratory Intensive Care Unit in North India. Respiratory Care, 54, 1679-1687.

[20] Melvin, M., Schiff, M.D. and Donald Massaro, M.D. (1967) Effect of Oxygen Administration by a Venturi Apparatus on Arterial Blood Gas Values in Patients with Respiratory Failure. The New England Journal of Medicine, 277, 950-953. https://doi.org/10.1056/NEJM196711022771803

[21] Zhu, G.-F., Wang, D.J., Liu, S., Jia, M. and Jia, S.-J. (2013) Efficacy and Safety of Noninvasive Positive Pressure Ventilation in the Treatment of Acute Respiratory Failure after Cardiac Surgery. Chinese Medical Journal, 126, 4463-4469.

[22] Auriant, I., Jallot, A., Herve, P., Cerrina, J., Le Roy Ladurie, F., Fournier, J.L., et al. (2001) Noninvasive Ventilation Reduces Mortality in Acute Respiratory Failure Following Lung Resection. American Journal of Respiratory and Critical Care Medicine, 164, 1231-1235. https://doi.org/10.1164/ajrccm.164.7.2101089

[23] Lemiale, V., Mokart, D., Resche-Rigon, M., et al. (2015) Effect of Noninvasive Ventilation vs Oxygen Therapy on Mortality among Immunocompromised Patients with Acute Respiratory Failure a Randomized Clinical Trial. JAMA, 314, 1711-1719. https://doi.org/10.1001/jama.2015.12402

[24] Ferrer, M., Esquinas, A., Leon, M., et al. (2003) Noninvasive Ventilation in Severe Hypoxemic Respiratory Failure: A Randomized Clinical Trial. American Journal of Respiratory and Critical Care Medicine, 168, 1438-1444.

https://doi.org/10.1164/rccm.200301-072OC 